\title{
Functioning Pancreatic Neuroendocrine Tumor
}

National Cancer Institute

\section{Source}

National Cancer Institute. Functioning Pancreatic Neuroendocrine Tumor. NCI

Thesaurus. Code C45840.

A low or intermediate grade well differentiated tumor with neuroendocrine differentiation that arises from the pancreas. It is characterized by the presence of a clinical syndrome that results from hormone hypersecretion. 